\title{
Saccharomyces cerevisiae cell wall products: The effects on gut morphology and performance of broiler chickens
}

\author{
M. Brümmer ${ }^{1 *}$, C. Jansen van Rensburg ${ }^{1}$ and C.A. Moran ${ }^{2 \#}$ \\ ${ }^{1}$ Department of Animal and Wildlife Sciences, University of Pretoria, Pretoria 0002, South Africa \\ ${ }^{2}$ North American Biosciences Centre, Alltech Inc., Nicholasville, KY, USA
}

\begin{abstract}
The aim of this study was to determine the effect of Bio-Mos ${ }^{\circledR}$ (Alltech Inc.), with or without the addition of a soluble mannan (MRF) (Alltech Inc.) on gastrointestinal health and performance of broiler chickens. A trial was conducted using seven different dietary treatments. It consisted of a negative control, 2 levels of Bio-Mos ${ }^{\circledR}(2 \mathrm{~g} / \mathrm{kg}$ and $4 \mathrm{~g} / \mathrm{kg}), 2$ levels of MRF $(0.1 \mathrm{~g} / \mathrm{kg}$ and $0.2 \mathrm{~g} / \mathrm{kg})$ and 2 treatments combining the cell wall preparations $\left(2 \mathrm{~g} / \mathrm{kg}\right.$ Bio-Mos ${ }^{\circledR}+0.1 \mathrm{~g} / \mathrm{kg}$ MRF and $4 \mathrm{~g} / \mathrm{kg}$ Bio-Mos ${ }^{\circledR}+0.2 \mathrm{~g} / \mathrm{kg}$ MRF). Dayold male broiler chicks were randomly allocated to the seven treatments and the trial extended over a 15 day period, upon which two chicks from each replicate were sacrificed and ileum samples taken. Results showed that the cell wall preparations had a numerically positive, but statistically non significant effect on feed conversion ratios. Histology results revealed significantly greater goblet cell densities and sizes for chicks receiving cell wall preparations than those of the control treatment chicks, while villi width and height measurements indicated no differences between treatments. From the results of this study it appears as if yeast cell wall preparations can contribute to the gastrointestinal health and performance of broiler chickens by affecting mucus secreting goblet cells in a favourable manner.
\end{abstract}

Keywords: Yeast, villi width and height, growth rate, goblet cells

\# Corresponding author. E-mail: cmoran@alltech.com

* Current address: Department of Animal and Food Sciences; University of Kentucky; Lexington, KY 40546, USA

\section{Introduction}

Over the past few years there has been increased concern amongst animal product consumers regarding the inclusion of antibiotics in animal diets. The use of a number of antibiotics for prophylactic or growth promoter purposes has therefore become restricted or banned from use (Dibner \& Richards, 2005; Castanon, 2007). At the same time enteric diseases remain a focal point where poultry production is concerned as they not only affect consumer health, but also result in production inefficiency (Patterson \& Burkholder, 2003). There has been movement within the industry towards the production of antibiotic-free products for consumers paying a premium for these products. However, the cost of poultry production without antibiotic growth promoters remains prohibitive as not all production facilities can focus on niche markets only and the majority of consumers cannot afford the premiums charged. Disease control also becomes problematic for large-scale production facilities when prophylactic antibiotic substances are eliminated. It is therefore obvious that alternatives to antibiotics must be investigated to keep poultry products affordable and safe for consumer use.

Without a healthy gastrointestinal tract a broiler would not be able to reach performance potential. Lengthened villi are generally associated with superior gut health as well as improved nutrient absorption (Sims et al., 2004). Development of the morphology of the gastrointestinal tract is greatly influenced by the diet of the animal (Santin et al., 2001). Due to the high cell turnover rate, the intestinal lining only has to be exposed to a specific dietary factor for a short period of time in order to observe changes in the structure of the mucosa (Iji et al., 2001). Zhang et al. (2005) observed greater villi height and superior ileal mucosa development at $21 \mathrm{~d}$ in chickens supplemented with a yeast cell wall product prepared from Saccharomyces cerevisiae.

Mannan oligosaccharides (MOS) are mannose-based carbohydrates found in the yeast cell wall and are capable of adsorbing enteropathogens (Spring et al., 2000). MOS have been shown to improve nutrient utilisation through stimulation of specific microbial populations in the gastrointestinal tract (Kocher et al., 2004), and increased surface area resulting from longer villi in turkeys (Sims, 2004) and rabbits (Mourão et 
al., 2006). Recently, Baurhoo et al. (2009) reported not only increased villi height, but also increased numbers of goblet cells in all sections of the small intestine on d 24 and d 34 in MOS supplemented broilers. The main function of the GC in the crypts and on the villi of the intestinal tract is the production of mucus, which forms a protective layer on the villi and gut mucosa (Padykula, 1977). Secreted mucus comprises mostly of mucin glycoproteins and was found to assist with transportation between the lumen and the epithelial cells and form an environment in which certain digestive processes could occur (Smirnov et al., 2004). The mucus also protects the intestinal lining from damage caused by gut micro flora, enteropathogenic activity, digestive processes and coarse dietary components (Smirnov et al., 2006).

Bio-Mos ${ }^{\circledR}$ (Alltech, Inc., Nicholasville, KY USA ) is a glucomannoprotein complex isolated from the outer cell wall of the yeast, Saccharomyces cerevisiae (Newman 1994). Mannan rich fraction (MRF) is a soluble extract of the yeast cell wall of Saccharomyces cerevisiae whereby the mannoproteins are separated from the other cell wall components. MRF contains a greater concentration of mannan reactive units (alpha 1,3 mannan) involved in agglutination and recognition of phagocytic cells. It is therefore postulated that MRF is more concentrated than Bio-Mos ${ }^{\circledR}$ and therefore could have a similar action at a lower level of inclusion.

The objective of the study was to investigate the effect of Bio-Mos ${ }^{\circledR}$ and MRF on the early development of the gut and performance of young broiler chickens. Bio-Mos ${ }^{\circledR}$ and MRF were also combined to investigate possible synergistic effects between mannose-based carbohydrates and mannoproteins. Morphometric variables were measured in the ileum and included: villi height, villi width, crypt depth, muscularis thickness and, based on preliminary data, goblet cell size and goblet cell density.

\title{
Materials and Methods
}

The experiment was executed as a complete randomised design. Two hundred and forty five day-old male broiler chicks were obtained from a local breeding farm. Upon arrival chicks were randomly assigned to 49 different pens. A total of seven treatments were applied, each treatment consisted of seven replicates, and five broilers per replicate. The experiment was conducted over a period of $15 \mathrm{~d}$ with performance evaluation (group-weighing and feed intake per pen) on $\mathrm{d} 7$ and 14 and ileum sampling on $\mathrm{d} 15$. The feed conversion ratio (FCR) for each pen was calculated from body weight gain and feed intake.

Each pen was fitted with a nipple drinker and tube feeder to allow ad libitum access to drinking water and feed. The room temperature was initially adjusted to $32{ }^{\circ} \mathrm{C}$ and then gradually lowered to reach approximately $26{ }^{\circ} \mathrm{C}$ by $\mathrm{d} 10$. Temperature was monitored on a daily basis and light was continuously provided for the duration of the experiment.

Chicks were fed a maize-soyabean based starter meal, fortified with minerals and vitamins (Table 1). The basal diet was mixed as a single batch to reduce diet variability after which the respective feed additive(s) were added to create the different treatments. The products were combined in Treatment 6 and Treatment 7 to investigate possible synergistic effects. The treatments were as follows:

\author{
Treatment 1: Negative control (no additive) \\ Treatment 2: Bio-Mos ${ }^{\circledR}(2 \mathrm{~g} / \mathrm{kg})$ \\ Treatment 3: Bio-Mos ${ }^{\circledR}(4 \mathrm{~g} / \mathrm{kg})$ \\ Treatment 4: MRF $(0.1 \mathrm{~g} / \mathrm{kg})$ \\ Treatment 5: MRF $(0.2 \mathrm{~g} / \mathrm{kg})$ \\ Treatment 6: Bio-Mos ${ }^{\circledR}(2 \mathrm{~g} / \mathrm{kg})+\operatorname{MRF}(0.1 \mathrm{~g} / \mathrm{kg})$ \\ Treatment 7: Bio-Mos ${ }^{\circledR}(4 \mathrm{~g} / \mathrm{kg})+\operatorname{MRF}(0.2 \mathrm{~g} / \mathrm{kg})$
}

Two chicks from each replicate, i.e. 14 chicks per treatment, were sacrificed on d 15. The intended section of the terminal ileum was removed and immediately rinsed with saline solution. The tissue sample was placed in buffered formalin (10\% neutral buffered formalin; Sigma-Aldrich, St Louis MO) for a period of $18 \mathrm{~h}$. Samples were then rinsed three times with deionised water, placed in $70 \%(\mathrm{v} / \mathrm{v})$ ethanol and set in paraffin blocks (University of Louisville, KY). Two intestinal samples were sectioned $(7 \mu \mathrm{m})$ per broiler and set on two different slides. 
Table 1 Ingredient composition $(\mathrm{g} / \mathrm{kg})$ of the basal diet

\begin{tabular}{lr}
\hline Ingredient & 533 \\
Maize & 380 \\
Soyabean meal, dehulled & 43.7 \\
Maize oil & 20.4 \\
Dicalcium phosphate & 12.5 \\
Limestone & 5.0 \\
Salt, ionized & 2.5 \\
DL-methionine & 2.5 \\
Vitamin and mineral premix & \\
Nutrient composition ${ }^{1}$ & 13.4 \\
AME (MJ/kg) & 229 \\
Crude protein & 12.5 \\
Lysine & 6.0 \\
Methionine & 3.7 \\
Cysteine & 10 \\
Calcium & 5 \\
Phosphorus & \\
\hline
\end{tabular}

${ }^{1}$ Formulated, not analysed, nutrient levels.

AME - apparent metabolisable energy.

One of each of these slides (i.e. one per broiler) was stained with hematoxylin and eosin (H\&E stain; University of Louisville, KY). H\&E stained intestinal sections were used to measure the crypt depth, villus height and width and muscularis externa thickness. Villus height was measured as the length between the villous-crypt axis and the tip of the villus. The villus width was measured at the midpoint between the villous-crypt axis and the tip of the villous. Crypt depth was measured from the villous-crypt axis to the base of the specific crypt. The thickness of the muscularis externa was measured from the base of the crypt to the base of the muscularis externa.

The other slides were stained using Alcian-Blue/Periodic Acid Schiff ( $\mathrm{pH} 2.5)$ to determine goblet cell size. A combination of Alcian Blue /Periodic Acid Schiff (AB/PAS) and Haematoxylin Gill 3X (Fisher Scientific, Kalamazoo, MI) were found to provide a clear, purple/blue image of the goblet cells and increased the accuracy with which the measurements could be made compared to AB/PAS alone. The staining method of Uni et al. (2003) was thus adapted for this experiment. Slides were deparaffinised and hydrated. Samples were then incubated in Alcian Blue-solution for $5 \mathrm{~min}$, followed by incubation in periodic acid solution for $10 \mathrm{~min}$, incubated in Schiffs reagent (Sigma-Aldrich) for $15 \mathrm{~min}$ and finally incubated in Haematoxylin Gill 3X (Fisher Scientific, Kalamazoo, MI) for $20 \mathrm{sec}$. In between each incubation period, slides were meticulously rinsed with deionised water. Slides were then dehydrated, cleared and mounted following standard methods (Fisher Protocol Mounting Media; Fisher Scientific). Goblet cell size was measured as the "cup" area of the goblet cells $\left(\mu \mathrm{m}^{2}\right)$. One hundred and fifty measurements (15 measurements on 10 villi) were made for each intestinal sample. Only perfect cross sections of the goblet cells were measured, i.e. the goblet cell had to show the cup and the tail area to be measured, and also had to touch the villi edge. When goblet cell numbers were low the maximum number of goblet cells that fulfilled in the selection criteria was measured. Goblet cell density was determined as the number of goblet cells per $10000 \mu^{2}$. All density measurements were taken from the midsection of the villus to make measurements comparable with one another. Only goblet cells found on the edge of the villus were counted for the density determination calculations and goblet cells had to show the "cup and tail portion" to be counted. 
Villi were photographed with a Nikon Spot Insight Colour camera (model \#3.2.0) and Spot Software (version 4.5) was used for all measurements.

Gut morphology measurements and FCR were analysed as a complete randomised design using the general linear model procedure of SAS (SAS, 1988). The following model was fitted to the gut morphology measurement data: $Y_{i j k}=\mu+T_{i}+d_{i j k}+e_{i j}$ where $Y_{i j k}$ is the dependent variable, $\mu$ is the overall mean, $T_{i}$ is the fixed effects of treatment, $d_{i j k}$ is the random effect of $k^{\text {th }}$ subsample in the $j^{\text {th }}$ experimental unit in the $i^{\text {th }}$ treatment, and $\mathrm{e}_{\mathrm{ij}}$ as random error for the $\mathrm{j}^{\text {th }}$ experimental unit in the $\mathrm{i}^{\text {th }}$ treatment. FCR data were analyzed using Duncan's Multiple Range Test. Statistical significance was set at $\mathrm{P}<0.05$. Variance homogeneity of the measurements was tested using the F-Max test at $\alpha=0.05 ; \mathrm{t}=7 ; \mathrm{v}=2$.

The experiment was conducted within standard ethical norms and no birds were subjected to undue stress.

\section{Results}

No significant differences were found in terms of bird weight and feed intake for the different treatments. The FCR, measured as $\mathrm{kg}$ feed/ $\mathrm{kg}$ body weight gain, is presented in Table 2. Numerical, but not significant $(\mathrm{P}>0.05)$, differences between treatments were observed for FCR. The numerically highest FCR was observed for the control group while the numerically lowest FCR was attained by the Bio-Mos ${ }^{\circledR}$ (4 $\mathrm{g} / \mathrm{kg}$ ) treatment group.

Table 2 Mean ( \pm s.d.) feed conversion ratio (FCR, $\mathrm{kg}$ feed/kg body weight gain) of broilers fed diets containing two mannose-based feed additives, alone or in combination, from 0 to $14 \mathrm{~d}$

\begin{tabular}{lc}
\hline Treatment & FCR \\
\hline Control (no additive) & $1.47( \pm 0.17)$ \\
Bio-Mos $(2 \mathrm{~g} / \mathrm{kg})$ & $1.42( \pm 0.13)$ \\
Bio-Mos $(4 \mathrm{~g} / \mathrm{kg})$ & $1.32( \pm 0.11)$ \\
$\operatorname{MRF}(0.1 \mathrm{~g} / \mathrm{kg})$ & $1.33( \pm 0.07)$ \\
$\operatorname{MRF}(0.2 \mathrm{~g} / \mathrm{kg})$ & $1.43( \pm 0.17)$ \\
$\operatorname{Bio}-M o s(2 \mathrm{~g} / \mathrm{kg})+\operatorname{MRF}(0.1 \mathrm{~g} / \mathrm{kg})$ & $1.34( \pm 0.09)$ \\
Bio-Mos $(4 \mathrm{~g} / \mathrm{kg})+\operatorname{MRF}(0.2 \mathrm{~g} / \mathrm{kg})$ & $1.35( \pm 0.11)$ \\
\hline
\end{tabular}

MRF - Mannan rich fraction.

Morphometric measurements from the H\&E stained slides are shown in Table 3. No significant differences were found for any of the measurements when compared to the control group.

A lower number of goblet cells and smaller goblet cell size were observed for the control group than for the rest of the treatment groups $(\mathrm{P}<0.01)$. The control group goblet cell density ranged from 8 to 19 goblet cells per $100 \mu \mathrm{m}$ villus length, while goblet cell size ranged from $38.51 \mu^{2}$ to $60.30 \mu \mathrm{m}^{2}$. In comparison goblet cell density in the treatment groups ranged from 10 to 27 goblet cells per 10000 $\mu \mathrm{m}^{2}$ villus area, with goblet cell size ranging from $61.21 \mu \mathrm{m}^{2}$ to $94.93 \mu \mathrm{m}^{2}$. A summary of the goblet cell measurements is presented in Table 4 and illustrated in Figure 1. No differences were found between treatment groups, including the combined treatments, possibly indicating similar mechanism of action of MRF and Bio-Mos. 
Table 3 Mean morphometric measurements $(\mu \mathrm{m})$ of ileal villi from broilers on d 15 fed diets containing two mannose-based feed additives, alone or in combination

\begin{tabular}{lllll}
\hline Treatment & VH & VW & CD & MT \\
\hline Control (no additive) & 417.44 & 123.7 & 86.34 & 337.34 \\
Bio-Mos $(2 \mathrm{~g} / \mathrm{kg})$ & 413.01 & 126.1 & 97.28 & 341.92 \\
Bio-Mos $(4 \mathrm{~g} / \mathrm{kg})$ & 403.67 & 128.0 & 90.96 & 322.05 \\
MRF $(0.1 \mathrm{~g} / \mathrm{kg})$ & 406.25 & 118.0 & 85.04 & 325.25 \\
MRF $(0.2 \mathrm{~g} / \mathrm{kg})$ & 411.86 & 132.4 & 91.88 & 331.62 \\
Bio-Mos $(2 \mathrm{~g} / \mathrm{kg})+$ MRF $(0.1 \mathrm{~g} / \mathrm{kg})$ & 423.03 & 124.3 & 92.29 & 338.48 \\
Bio-Mos $(4 \mathrm{~g} / \mathrm{kg})+$ MRF $(0.2 \mathrm{~g} / \mathrm{kg})$ & 431.71 & 137.4 & 93.67 & 340.47 \\
\hline Standard Error Difference & 20.76 & 12.46 & 3.84 & 28.31 \\
P-value & 0.386 & 0.220 & 0.910 & 0.731
\end{tabular}

VH - villi height; VW - Villi width; CD - crypt depth; MT - Muscularis thickness.

MRF - Mannan rich fraction.

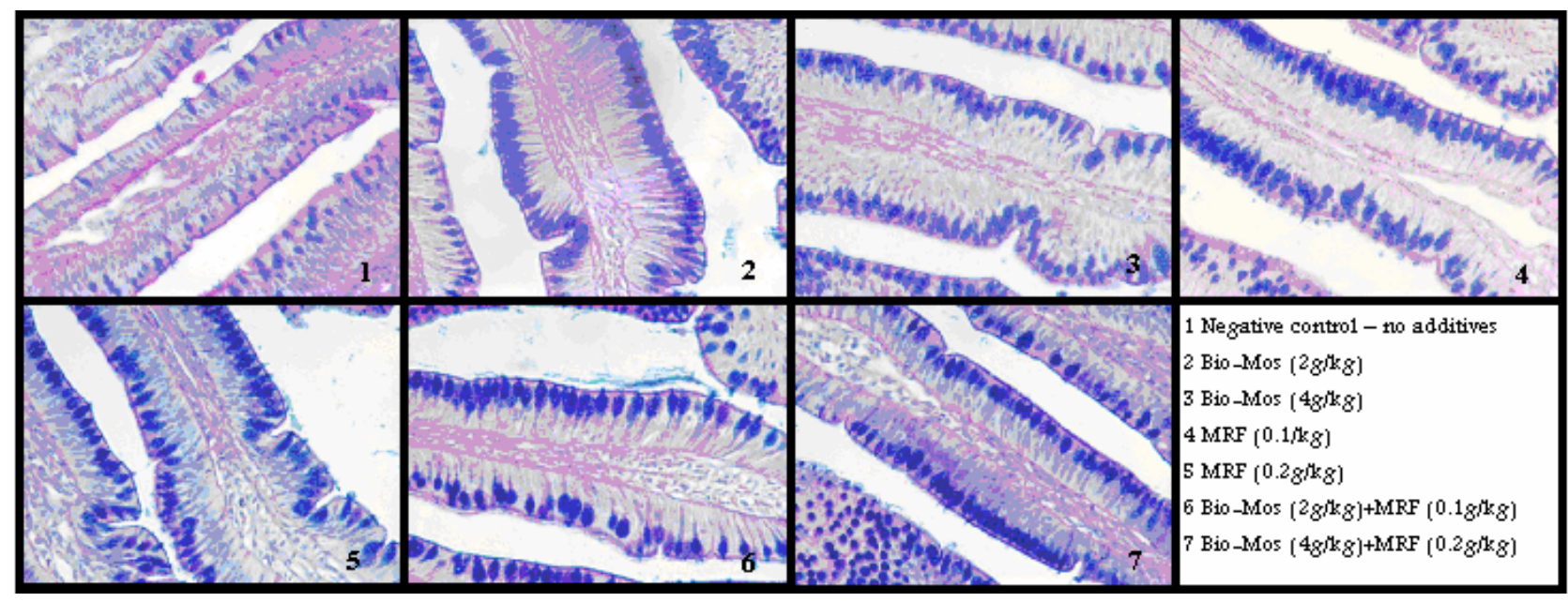

Figure 1 Photomicrographs taken at $400 \mathrm{X}$ magnifications illustrating the differences observed between treatments for both ileal goblet cell size and density.

\section{Discussion}

The feed conversion ratios reported for this study showed numerical but non-significant differences between the treatments. Similarly, Yang et al. (2007) reported broiler FCRs to be unaffected by MOS supplementation. Regardless of lack of treatment effect, recorded FCRs were good and the broilers remained in excellent health for the duration of this trial.

Morphometric analysis revealed no difference in villi height and width, crypt depth or muscle thickness between the treatment groups. This indicated that no changes occurred in villi morphology between treatments, and thus absorptive surface area in the small intestine. Yang et al. (2007) also reported no effect of MOS supplementation on gut morphology in chickens.

Goblet cell size and density was affected by treatment, with larger and greater numbers of goblet cells observed in all treatment groups in comparison to the control groups. Similar villi height and width between treatments indicated no stunting or abnormal morphology that could have influenced goblet cell measurements. 
Table 4 Mean $\left( \pm\right.$ s.e.) measurements of ileal goblet cell $\left(\mathrm{GC} ; \mu \mathrm{m}^{2}\right)$ size and goblet cell density (number of goblet cells per $10000 \mu \mathrm{m}^{2}$ villus area) from broilers on $\mathrm{d} 15$, fed diets containing two mannose-based feed additives, alone or in combination

\begin{tabular}{ccc}
\hline Treatment & Average GC size $\left(\mu \mathrm{m}^{2}\right)$ & $\begin{array}{c}\text { Average GC density } \\
\text { (number goblet cells per } \\
\left.10000 \mu \mathrm{m}^{2} \text { villus area }\right)\end{array}$ \\
\hline Control (no additive) & $47.5^{\mathrm{a}}( \pm 0.51)$ & $14.1^{\mathrm{a}}( \pm 0.43)$ \\
Bio-Mos $(2 \mathrm{~g} / \mathrm{kg})$ & $77.8^{\mathrm{b}}( \pm 1.07)$ & $20.5^{\mathrm{b}}( \pm 0.43)$ \\
Bio-Mos $(4 \mathrm{~g} / \mathrm{kg})$ & $75.6^{\mathrm{b}}( \pm 1.25)$ & $19.4^{\mathrm{b}}( \pm 0.41)$ \\
MRF $(0.1 \mathrm{~g} / \mathrm{kg})$ & $76.5^{\mathrm{b}}( \pm 1.25)$ & $19.9^{\mathrm{b}}( \pm 0.39)$ \\
MRF $(0.2 \mathrm{~g} / \mathrm{kg})$ & $83.4^{\mathrm{b}}( \pm 0.69)$ & $20.0^{\mathrm{b}}( \pm 0.29)$ \\
Bio-Mos $(2 \mathrm{~g} / \mathrm{kg})+\mathrm{MRF}(0.1 \mathrm{~g} / \mathrm{kg})$ & $77.1^{\mathrm{b}}( \pm 1.29)$ & $20.8^{\mathrm{b}}( \pm 0.29)$ \\
Bio-Mos $(4 \mathrm{~g} / \mathrm{kg})+\mathrm{MRF}(0.2 \mathrm{~g} / \mathrm{kg})$ & $77.9^{\mathrm{b}}( \pm 1.21)$ & $19.8^{\mathrm{b}}( \pm 0.31)$ \\
\hline Standard Error Difference & 2.20 & 1.20 \\
P-value & 0.002 & 0.007
\end{tabular}

\footnotetext{
${ }^{\mathrm{a}, \mathrm{b}}$ Column means with different superscripts differ significantly at $\mathrm{P}<0.05$. MRF - Mannan rich fraction.
}

Goblet cells are produced in the crypts of the intestinal tract and over a period of approximately three days goblet cells migrate up along the sides of the villi, towards the villi tip where they will eventually be sloughed and released into the intestinal lumen (Uni et al., 2003). These goblet cells are replaced in a continuous manner (Uni et al., 2003). Most of the mucus production and mucus release from the goblet cell occur within the second and third day of these cells' life cycle (Padykula, 1977). The thickness of the mucus layer could be described as the difference between the amount of mucus released and the rate of mucus degradation, which take place as a result of enzymatic activity and physical abrasion (Smirnov et al., 2004). Cytokines, bacterial products and other growth factors were reported to regulate the mucin genes at the transcriptional level (Smirnov et al., 2004). Experiments involving fasting of chickens for specified periods of time resulted in enlarged goblet cells as well as an increase in the density of goblet cells (Uni et al., 2003). Enlarged goblet cells indicate an increase in mucus storage in the goblet cells (Smirnov et al., 2005).

A possible explanation for the observed results of this trial was postulated from research conducted by Uni et al. (2003) and Smirnov et al. $(2004 ; 2005 ; 2006)$. Mucus was reported to function as a protective barrier against enteropathogens. Mucus was also found to facilitate the absorption of certain minerals. However, nutrients must cross this layer of mucus to reach the enterocytes for absorption to occur. If the mucus layer is too thick it could act as a barrier to nutrient absorption. However, FCR attained in this trial indicated nutrient uptake was not adversely affected by treatment. Further, the enlargement of goblet cells has been reported to indicate a greater storage capacity for mucin in the goblet cell. Yeast cell wall preparations used in this trial increased the goblet cell size and density, indicating a change in the goblet cell, but similar FCR suggests non-significant change in the intestinal mucus layer. The observed changes in goblet cells over a period of 15 days could therefore imply an improved capacity of the gastrointestinal tract to respond to pathogenic insult through increased mucus storage without increased secretion to the point that FCR was affected. It should be considered that the mucus staining procedure used to stain for the goblet cell would not have stained empty goblet cells, and therefore it is possible that actual goblet cell density was not affected to the same extent as mucus production, re-emphasizing an improved mucus storage capacity in treatment birds.

Enlarged goblet cells were also observed in chickens receiving feed supplemented with the probiotic Lactobacillus and Bifidobacterium species (Smirnov et al., 2005). The composition of the microbial population in the intestine plays an important role in mucin degradation, as some microbial species, such as Bifidobacterium species, possess what is referred to as mucin-degrading glycosidase and glycosulfatases. 
Baurhoo et al. (2009) stated that Lactobacillus and Bifidobacterium species colonisation of the gastrointestinal tract have been associated with increased villi height, as well as the ability to stimulate mucus production. In this study we did not look at bacterial colonisation, but Baurhoo et al. (2009) reported higher Bifidobacterium species concentrations in MOS supplemented broilers together with the increase in goblet cell numbers.

Due to time restrictions no measurements were made to determine bacterial colonisation of the gastrointestinal tract or thickness of the mucus layer and the assumptions made above are theoretical only, based on goblet cells size and the feed conversion ratios that were observed in this trial.

\section{Conclusion}

The addition of Bio-Mos ${ }^{\circledR}$, a soluble mannan product or the combination of the two to the diet of day old broiler chicks affected the morphology of the small intestines by inducing enlargement of the goblet cells and increased density of goblet cells without affecting the villus height or width. Goblet cells secrete mucus, which acts as a protective barrier against enteropathogens, digestive enzymes and harsh feed particles. The goblet cell changes observed, may indicate enhanced protection of the gut epithelium against intestinal pathogenic insult and abrasive feed components without affecting nutrient absorption negatively.

Further research in both experimental and commercial settings, with higher stress levels and pathogenic insult is necessary to the fully understand the extent of this contribution.

\section{Acknowledgement}

North American Biosciences Centre, Alltech Inc., Nicholasville, KY, USA for sponsoring and directing the research at their facilities. Statistical analysis prepared by J. Tricarico (North American Biosciences Centre, Alltech Inc., Nicholasville, KY, USA) and R.J. Coertze (Department Animal and Wildlife Sciences, University of Pretoria, South Africa).

\section{References}

Baurhoo, B., Ferket, P.R. \& Zhao, X., 2009. Effects of diets containing different concentrations of mannanoligosaccharide or antibiotics on growth performance, intestinal development, cecal and litter microbial populations, and carcass parameters of broilers. Poult. Sci. 88, 2262-2272.

Castanon, J.I.R., 2007. History of the use of antibiotic as growth promoters in European poultry feeds. Poult. Sci. 86, 2466-2471.

Dibner, J.J. \& Richards, J.D., 2005. Antibiotic growth promoters in agriculture: History and mode of action. Poult. Sci. 84,634-643.

Iji, P.A., Saki, A.A. \& Tivey, D.R., 2001. Intestinal structure and function of broiler chickens on diets supplemented with a mannan oligosaccharide. J. Sci. Food Agric. 81, 1186-1192.

Kocher, A., Canolly, A., Zawadzki, J. \& Gallet, D., 2004. The challenge of finding alternatives to antibiotic growth promoters. International Society for Animal Hygiene-Saint Malo 2004. pp. 227-229.

Mourão, J.L., Pinheiro, V., Alves, A., Guedes, C.M., Pinto, L., Saavedra, M.J., Spring, P. \& Kocher, A., 2006. Effect of mannan oligosaccharides on the performance, intestinal morphology and cecal fermentation of fattening rabbits. Anim. Feed Sci. Technol. 126, 107-120.

Newman, K., 1994. Mannan-oligosaccharides: Natural polymers with significant impact on the gastrointestinal microflora and the immune system. In: Biotechnology in the Feed Industry: Proc. Alltech's Tenth Annual Symposium. Eds Lyons, T.P. \& Jacques, K.A., Nottingham University Press, Nottingham, UK. pp. 167-174.

Padykula, H.A., 1977. Histology (4th ed.). Eds Weiss, L. \& Greep, R.O., McGraw-Hill Book Company, NY, USA. pp. 681-686.

Patterson, J.A. \& Burkholder, K.M., 2003. Application of prebiotics and probiotics in poultry production. J. Poult. Sci. 82, 627-631.

Pettigrew, J.E., Miguel, J.C. \& Carter, S., 2005. Bio-Mos in sow diets: Performance responses and economics. Proc. Alltech's $21^{\text {st }}$ Annual Symposium. Eds Jacques, K.A. \& Lyons, T.P., Nottingham University Press. pp. 213-220.

Santin, E., Maiorka, A. \& Macari, M., 2001. Performance and intestinal mucosa development of broiler chickens fed diets containing saccharomyces cerevisiae cell wall. J. Appl. Poult. Res. 10, 236-244. 
Sims, M.D., Dawson, K.A., Newman, K.E., Spring, P. \& Hooge, D.M., 2004. Effects of dietary mannan oligosaccharide, bacitracin methylene disalicylate, or both on the live performance and intestinal microbiology of turkeys. Poult. Sci. 83, 1148-1154.

Smirnov, A., Sklan, D. \& Uni, Z., 2004. Mucin dynamics in the chick small intestines are altered by starvation. J. Nutr. 134, 736-742.

Smirnov, A., Perez, R., Amit-Romach, E., Sklan, D. \& Uni, Z., 2005. Mucin dynamics and microbial populations in the chicken small intestine are change by dietary probiotic and antibiotic growth promoter supplementation. J. Nutr. 135, 187-192.

Smirnov, A., Tako, E., Ferket, P.R. \& Uni, Z., 2006. Mucin gene expression and mucin content in the chicken intestinal goblet cells are affected by in ovo feeding of carbohydrates. J. Poult. Sci. 85, 669-673.

Spring, P., Wenk, C., Dawson, K.A. \& Newman, K.E., 2000. The effects of dietary mannan oligosaccharides on caecal parameters and the concentration of enteric bacteria in the caeca of salmonella challenged broiler chicks. Poult. Sci. 79, 205-211.

Uni, Z., Smirnov, A. \& Sklan, D., 2003. Pre- and posthatch development of goblet cells in the broiler small intestine: Effects of delayed access to feed. J. Poult. Sci. 82, 320-327.

Yang, Y., Iji, P.A., Kocher, A., Mikkelson, L.L. \& Choct, M., 2007. Effects of mannanoligosaccharides on growth performance, the development of gut microflora, and gut function of broiler chicks raised on new litter. J. Appl. Poult. Res. 16, 280-288.

Zhang, A.W., Lee, B.D., Lee, S.K., Lee, K.W., An, G.H., Song, K.B. \& Lee, C.H., 2005. Effects of yeast (Saccharomyces cerevisiae) cell components on growth performance, meat quality, and ileal mucosa development of broiler chicks. Poult. Sci. 84, 1015-1021. 